\title{
Environmentally Assisted Stress Corrosion Cracking
}

\author{
SRUJAN ROKKAM,,${ }^{1,5}$ RAUL B. REBAK, ${ }^{2}$ BAI CUI, ${ }^{3}$ \\ and SEBASTIEN DRYEPONDT ${ }^{4}$
}

1.-Advanced Cooling Technologies, Inc., Lancaster, PA, USA. 2.-GE Global Research, Niskayuna, NY, USA. 3.-University of Nebraska-Lincoln, Lincoln, NE, USA. 4.-Oak Ridge National Laboratory, Oak Ridge, TN, USA. 5.—e-mail: srujan.rokkam@1-act.com

Editor's Note: Due to an editorial processing error, this introduction to the "Environmentally Assisted Stress Corrosion Cracking" special topic in the August issue was not printed. Please follow the embedded link to access the articles in that topic.

Environmentally assisted cracking (EAC) is an area of growing concern for broad range of aerospace, industrial, nuclear and defense applications. Structural components in these applications are subject to material degradation due to EAC phenomena like stress corrosion cracking (SCC), hydrogen $(\mathrm{H})$ embrittlement, corrosion fatigue $(\mathrm{CF})$ and liquid metal embrittlement (LME). In recent years, there has been renewed interest in understanding these EAC phenomena in diverse applications, assessing materials compatibility and developing prediction capabilities.

The August 2017 topic, "Environmentally Assisted Stress Corrosion Cracking", provides $J O M$ readers with interesting reading material and updates addressing recent developments in understanding, quantifying and mitigating EAC phenomena, as well as investigation of specific material-environment system.

To foster a discussion on recent advances in understanding problems of EAC as well as advances in modeling and experimental studies, a symposium on "Environmental Assisted Cracking: Theory and Practice" was held at the TMS 2017 Annual Meeting in San Diego, California. With 46 contributions in the form of oral and poster presentations, the symposium offered a platform for scientific interactions on a wide range of topics pertaining to EAC phenomena. Subsequently, authors of the symposium were invited to publish their work in JOM under the special topic of "Stress Corrosion Cracking". Given the high quality papers received in the broad area of EAC, the topic has been expanded to

Srujan Rokkam is the JOM advisor for the Corrosion \& Environmental Effects Committee of the TMS Structural Materials Division, and guest editor for the topic Stress Corrosion Cracking of Metals in this issue. encompass broader reports under the banner of "Environmentally Assisted Stress Corrosion Cracking".

The six articles featured in this special topic highlight the recent advances in assessment, evaluation of EAC phenomena, and understanding of the corrosion physics. Three articles have a focus on SCC and the remaining three have a focus on $\mathrm{H}$ embrittlement phenomena. With contributors from both academic and industrial communities this topic aims to bring together researchers with common scientific and research interests on EAC phenomena.

The first article by Mohammed Masoumi et al., presents a study on the effect of grain orientation and boundary distributions on hydrogen induced cracking (HIC) in low carbon content steels. Using $\mathrm{x}$-ray and electron backscattered diffraction techniques, the authors investigated HIC corrosion as function of individual crystal orientations and grain boundaries of the steel samples. Their findings demonstrate that controlling the crystallographic texture and boundary distribution types in bodycentered cubic systems could lead to an improvement in HIC resistance.

The article by Moeko Hattori et al. investigates the role of $\mathrm{H}$-enhanced lattice defects on $\mathrm{H}$-embrittlement in $\times 80$ pipeline steel. Using thermal desorption and fracture surface analysis, the authors investigate the susceptibility of $\mathrm{H}$-embrittlement due to strain induced lattice defects. Their findings indicate that hydrogen plays a significant role in promoting the formation of vacancy type defects during plastic deformation immediately prior to fracture at low crosshead speeds.

The article by Yugo Ashida et al. provides an industrial perspective on assessment of EAC phenomena and their impact three application areas: corrosion and cracking of carbon steels in automotive applications, EAC of iron- and nickel-based alloys in salt production and processing, and EAC of iron- and nickel-based alloys in supercritical water. 
With a focus on current industrial level understanding of the root cause, controlling factors affecting the susceptibility to cracking and research efforts (past and ongoing) within each industry, the authors present a discussion on aspects of corrosion fatigue, hydrogen assisted cracking and stress corrosion cracking.

The article by Matthew McMahon et al. aims to improve the understanding of the intergranular stress corrosion cracking (IG-SCC) phenomenon in $\mathrm{Al}-\mathrm{Mg}$ alloys by testing the efficacy of applied potential control in highly aggressive environments. Using a correlation between bulk polarization parameters and the IG-SCC behavior, the authors demonstrate that bulk environment influences the development of crack tip chemistry for an AA5xxxseries $\mathrm{Al}-\mathrm{Mg}$ alloy. The findings demonstrate the mitigation of IG-SCC by control of electrochemical potential. The study advocates development of coatings systems using metal pigments that can act as sacrificial anodes and in turn provide cathodic protection to marine structures.

The article by Mansa Rajagopalan et al. provides an atomistic-scale investigation on the role of grain boundaries (GBs) in hydrogen segregation behavior in iron $(\mathrm{Fe})$. Using molecular statics simulations the energetics associated with hydrogen binding and segregation are investigated at different sites and as a function of distance from the GB. The study also illustrates a statistical model that builds on information gained from the atomistic calculations and is capable of predicting segregation behavior of the solute atoms across the various sites (interstitial and substitutional) of the GB. Developing such atomistic insights could be a key to revisiting the models of $\mathrm{H}$-segregation behavior in metals and alloys.

The article by Sudhanshu Singh et al. investigates the in situ material behavior in $\mathrm{Al} 7075$ alloys under combined effect of stress and corrosive environments. Using a recently developed $\mathrm{x}$-ray microtomography based approach the authors characterize three-dimensional (3D) crack growth due to stress corrosion cracking (in moisture, de- ionized water) and corrosion fatigue (in EXCO solution). The approach is non-destructive in nature and is able to capture details on sub-surface cracks, crack advance, evolution of hydrogen and corrosion products. Such methods can enable revisiting our fundamental understanding and facilitate improved description of environmental assisted cracking.

The following articles are published under the topic Environmentally Assisted Stress Corrosion Cracking in the August 2017 issue (vol. 69, no. 8) of $J O M$ and can be accessed via the JOM page at http://link.springer.com/journal/11837/69/8/page/1:

- "Effect of Grain Orientation and Boundary Distributions on Hydrogen-Induced Cracking in Low-Carbon-Content Steels" Mohammad Masoumi, Hana Livia Frota Coelho, Sérgio Souto Maior Tavares, Cleiton Carvalho Silva, and Hamilton Ferreira Gomes de Abreu.

- "The Role of Hydrogen-Enhanced Strain-Induced Lattice Defects on Hydrogen Embrittlement Susceptibility of X80 Pipeline Steel" M. Hattori, H. Suzuki, K. Takai, and Y. Seko.

- "An Industrial Perspective on Environmentally Assisted Cracking of Some Commercially Used Carbon Steels and Corrosion-Resistant Alloys" Yugo Ashida, Yuzo Daigo, and Katsuo Sugahara.

- "Mitigation of Intergranular Stress Corrosion Cracking in $\mathrm{Al}-\mathrm{Mg}$ by Electrochemical Potential Control" M.E. McMahon, J.R. Scully, and J.T. Burns.

- "Energetics of Hydrogen Segregation to $\alpha-\mathrm{Fe}$ Grain Boundaries for Modeling Stress Corrosion Cracking" M. Rajagopalan, I. Adlakha, M.A. Tschopp, and K.N. Solanki.

- "In Situ X-ray Microtomography of Stress Corrosion Cracking and Corrosion-Fatigue" Sudhanshu S. Singh, Tyler J. Stannard, Xianghui Xiao, and Nikhilesh Chawla.

The organizers would like to thank the support extended by the Corrosion and Environmental Effects Committee (CEEC), the Mechanical Behavior of Materials Committee (MBMC) of the TMS and the JOM editorial office. 